ARTICLE

\title{
The genetic basis and fitness consequences of sperm midpiece size in deer mice
}

Heidi S. Fisher ${ }^{1, \dagger}$, Emily Jacobs-Palmer ${ }^{1}$, Jean-Marc Lassance ${ }^{1} \&$ Hopi E. Hoekstra ${ }^{1}$

An extensive array of reproductive traits varies among species, yet the genetic mechanisms that enable divergence, often over short evolutionary timescales, remain elusive. Here we examine two sister-species of Peromyscus mice with divergent mating systems. We find that the promiscuous species produces sperm with longer midpiece than the monogamous species, and midpiece size correlates positively with competitive ability and swimming performance. Using forward genetics, we identify a gene associated with midpiece length: Prkar1a, which encodes the R1 $\alpha$ regulatory subunit of PKA. R1 $\alpha$ localizes to midpiece in Peromyscus and is differentially expressed in mature sperm of the two species yet is similarly abundant in the testis. We also show that genetic variation at this locus accurately predicts male reproductive success. Our findings suggest that rapid evolution of reproductive traits can occur through cell type-specific changes to ubiquitously expressed genes and have an important effect on fitness.

\footnotetext{
${ }^{1}$ Department of Organismic \& Evolutionary Biology, Department of Molecular \& Cellular Biology, Museum of Comparative Zoology, Howard Hughes Medical Institute, Harvard University, 16 Divinity Ave, Cambridge, MA 02138, USA. † Present address: Department of Biology, University of Maryland, College Park, MD 20742, USA. Correspondence and requests for materials should be addressed to H.E.H. (email: hoekstra@oeb.harvard.edu).
} 
T he remarkable diversity of male reproductive traits observed in nature is often attributed to the evolutionary forces of sexual conflict, sperm competition and sperm precedence $^{1-4}$. However, the genetic mechanisms that enable reproductive traits to respond to changes in selective regime are often unknown. Moreover, because most genes expressed in reproductive organs (for example, testis) are also expressed elsewhere in the body 5,6 , genetic changes that result in reproductive trait modification can potentially lead to negative pleiotropic consequences in either the opposite sex or in other tissues. Despite these constraints, reproductive phenotypes show striking and often rapid divergence, and can promote speciation ${ }^{7}$.

Two closely related Peromyscus rodents with highly divergent mating systems show marked variation in male reproductive traits $^{8-11}$. Within the genus, the deer mouse, $P$. maniculatus, is considered one of the most promiscuous species: both sexes mate with multiple partners, often in overlapping series just minutes apart $^{12}$, and females frequently carry multiple-paternity litters in the wild ${ }^{13}$. By contrast, its sister species, the old-field mouse, $P$. polionotus, is strictly monogamous as established from both behavioural $^{14}$ and genetic data ${ }^{15}$. Moreover, relative testis size is roughly three times larger in $P$. maniculatus than in $P$. polionotus ${ }^{11}$, consistent with the well-documented relationship between relative testis size and level of sperm competition in rodents ${ }^{16}$. Therefore the competitive environments experienced by sperm of $P$. maniculatus and $P$. polionotus males represent divergent selective regimes.

The factors that regulate mammalian reproductive success are numerous and complex, yet when sperm from multiple males compete for a limited number of ova, the quality of each male's sperm can influence who will sire offspring ${ }^{3}$. Under intense competition, sperm motility can be a critical determinant of success ${ }^{17}$. Previous studies have shown that $P$. maniculatus sperm swim with greater velocity than $P$. polionotus ${ }^{9}$. A primary energy source for motility is acquired by oxidative phosphorylation in the mitochondria, which are located within the sperm midpiece ${ }^{18}$. The size of the midpiece is thus predicted to positively influence flagellar thrust and sperm velocity ${ }^{19}$ and, indeed, evidence across multiple taxa support the relationship between midpiece size and speed $^{20-22}$.

In this study, we examine the relationship between sperm midpiece length, swimming performance and reproductive success in $P$. maniculatus, $P$. polionotus, and a hybrid population. We then identify a single gene of large effect that regulates the phenotypic difference in sperm midpiece length between the two focal species, and show how allelic variation at this locus influences sperm swimming velocity and ultimately, male fertility.

\section{Results}

Sperm morphology and performance. We first measured four sperm traits of mice taken from our laboratory colonies of the two focal species, $P$. maniculatus and $P$. polionotus (Fig. 1a). We found that sperm head size does not differ between these species (Fig. 1b,c), but $P$. maniculatus sperm have longer flagella than $P$. polionotus (Fig. $1 \mathrm{~d}$; $t$-test: $P=8 \times 10^{-11}, d f=9, n=10 \mathrm{sperm} /$ male). More specifically, the midpiece region of the flagellum is significantly longer in $P$. maniculatus sperm than in $P$. polionotus (Fig. 1e; $t$-test: $\left.P=3 \times 10^{-7}, d f=9, n=10 \mathrm{sperm} / \mathrm{male}\right)$. These data are consistent with morphological differences in sperm from wild-caught $P$. maniculatus and $P$. polionotus ${ }^{10}$.

Indeed, sperm from the promiscuous $P$. maniculatus males swim with greater velocity (straight-line velocity [VSL]) than sperm of the monogamous $P$. polionotus ( $t$-test: $P=0.017, d f=8$, $n=76-549 \mathrm{sperm} / \mathrm{male})$, consistent with our previous results? Two other means of measuring sperm swimming performance,

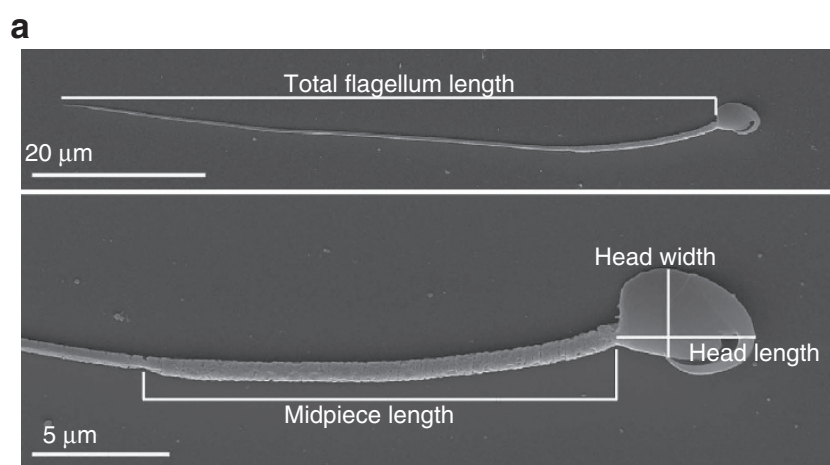

b

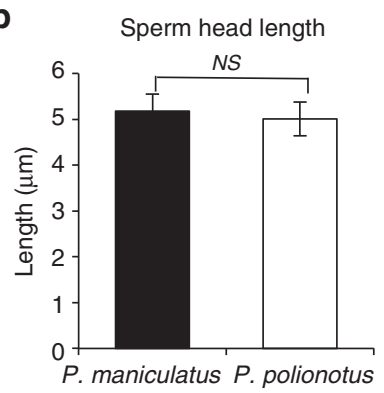

C

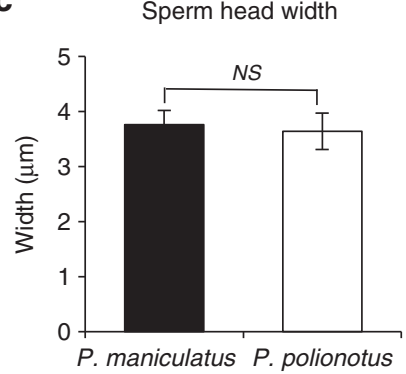

d
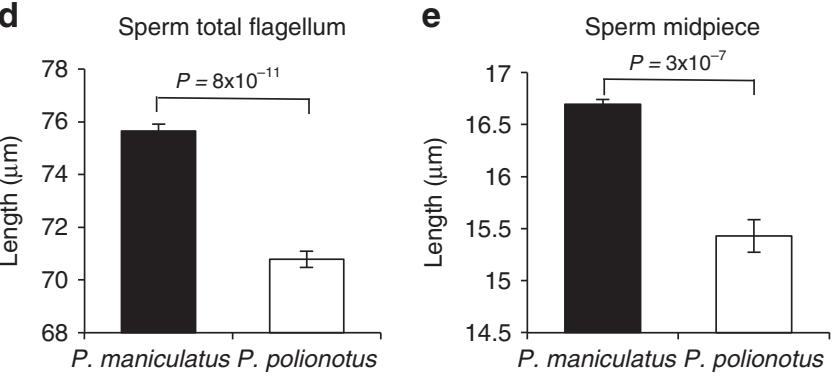

Figure 1 | Peromyscus sperm morphology. (a) Scanning electron micrographs of a mature $P$. maniculatus sperm cell with morphological features labelled. Mean \pm s.e. of $P$. maniculatus and $P$. polionotus sperm (b) head length, (c) head width, (d) total flagellum length and (e) midpiece length ( $n=10$ males; $n=10$ sperm/male; $t$-test). Sperm head and width do not differ significantly, yet $P$. maniculatus total flagellum and midpiece length are significantly longer than those in $P$. polionotus sperm. Note truncated $y$ axes. $N S=P$ value $>0.05$.

curvilinear velocity (VCL; $t$-test: $P=0.0024, d f=8, n=76-549$ sperm/male) and average path velocity (AVP; $t$-test: $P=0.0039$, $d f=8, n=76-549$ sperm/male), showed a similar difference as in the VSL results. Since all three velocity measures were consistent and are non-independent measurements, we focused on the most conservative estimate, VSL, in subsequent analyses (Supplementary Fig. 1).

To assay the relationship between Peromyscus midpiece length and swimming performance in a competitive context, we next conducted a series of swim-up assays, a clinical technique used to screen for highly motile spermatozoa that are most likely to achieve fertilization ${ }^{23}$. We tested sperm with variable midpiece lengths by centrifuging cells and collecting sperm best able to swim towards the surface through a viscous media. We first competed sperm from two heterospecific males ( $P$. maniculatus versus $P$. polionotus), which as a single mixed sample offers the greatest range of sperm morphology, and found that the most motile sperm had a significantly longer midpiece (Fig. 2; $t$-test: $P=3.28 \times 10^{-4}, d f=11 ; n=20 \mathrm{sperm} /$ trial). We found a strikingly similar result when the competitions involved sperm 


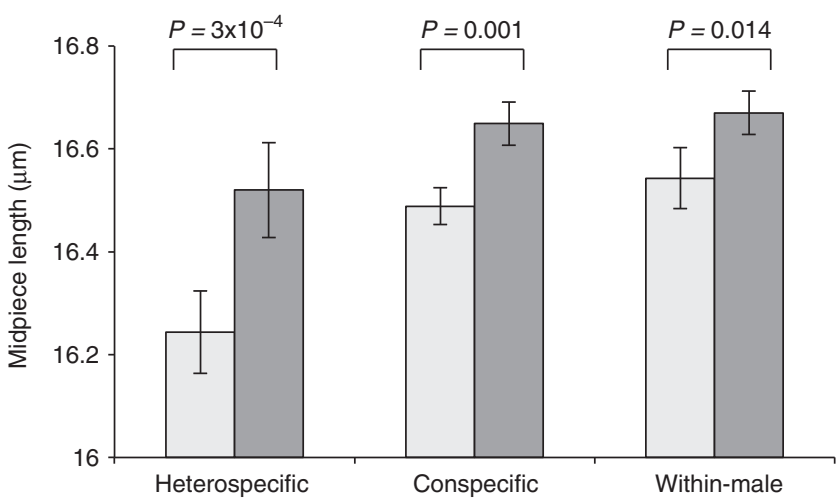

Figure 2 | Competitive sperm swim-up assays. Mean \pm s.e. of sperm collected prior to spinning (pre-spin; light grey bars) and from the centrifuged sample surface (post-spin; dark grey bars) in heterospecific (P. maniculatus versus $P$. polionotus; $n=12$ trials), conspecific (P. maniculatus versus $P$. maniculatus; $n=15$ trials), and within-male (P. maniculatus; $n=19$ trials) competitive swim-up assays. In all three assays, the mean midpiece length ( $n=20$ sperm/sample) of competitive sperm collected following centrifugation was significantly longer than those entering ( $t$-test). Note truncated $y$ axis. from two unrelated conspecific males ( $P$. maniculatus versus $P$. maniculatus), representing a more biologically relevant competition (Fig. 2; $t$-test: $P=0.001, d f=14 ; n=20 \mathrm{sperm} /$ trial), and even within-male competitions ( $P$. maniculatus) in which all sperm were harvested from a single male for each trial but still showed variation in midpiece length (Fig. 2; $t$-test: $P=0.014, d f=18 ; n=20 \mathrm{sperm} /$ trial). In total, these results suggest that sperm with larger midpiece regions are more motile, and thus more likely to achieve fertilization ${ }^{16,23}$, whether they are competing against heterospecific, conspecific or even of other sperm produced by the same male.

Genetic mapping of sperm midpiece length. Next, to dissect the genetic basis of adaptive differences in sperm morphology, we performed a genetic intercross between $P$. maniculatus and $P$. polionotus to produce 300 second-generation hybrid $\left(\mathrm{F}_{2}\right)$ male offspring. We then genotyped each $\mathrm{F}_{2}$ male at 504 anonymous loci throughout the genome. We identified a single chromosomal region significantly associated with midpiece length variation on linkage group 4 (LG4; Fig. 3; on the basis of logarithm of odds [LOD], significance determined by a genome-wide permutation test with $\alpha=0.01$ ). This single region of the genome explains $33 \%$ of sperm midpiece length variation in the $\mathrm{F}_{2}$ hybrids, and largely

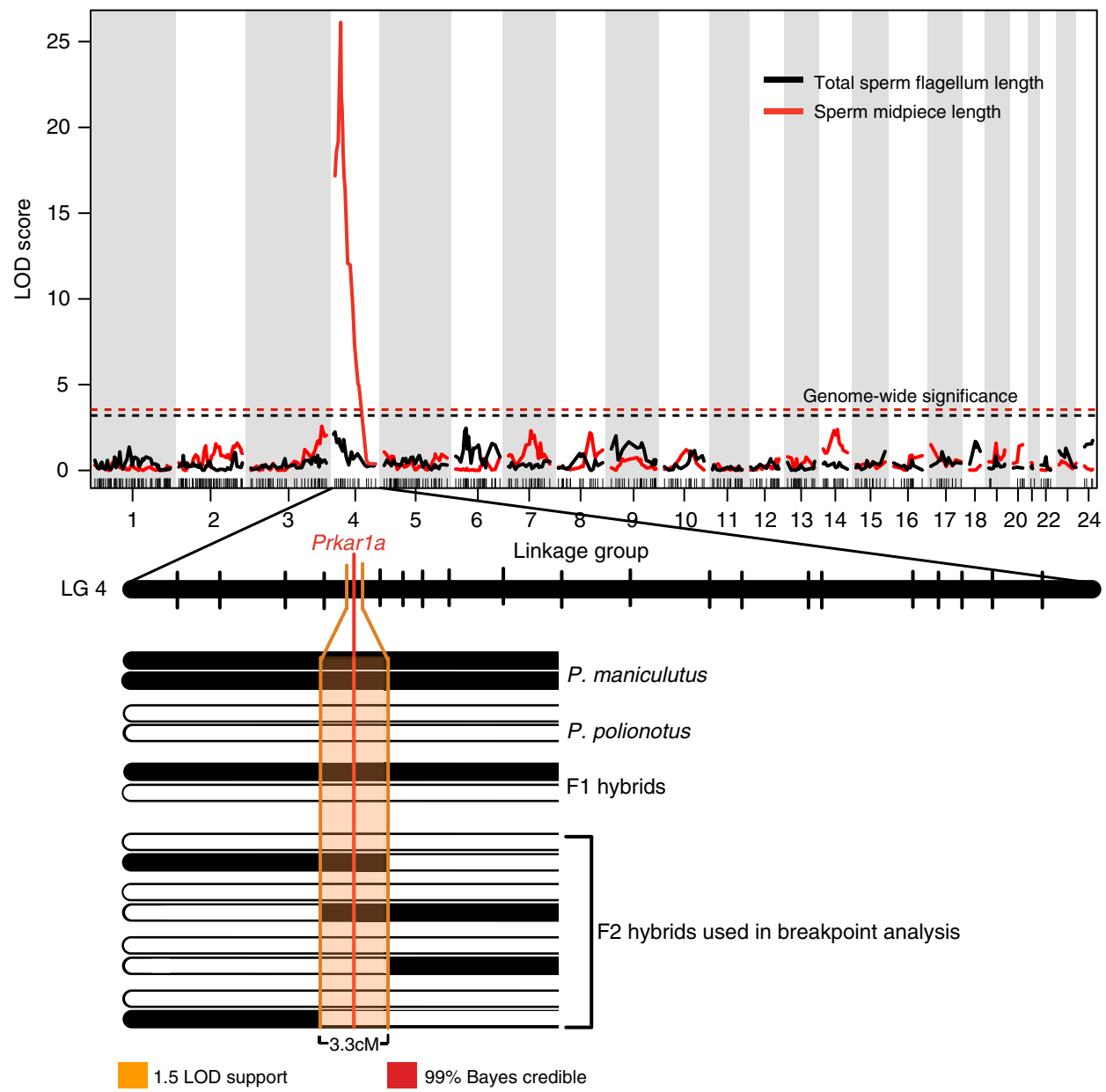

Figure 3 | Genetic mapping of sperm morphology. Association between genome-wide SNP markers and total sperm flagellum length (black) and midpiece length (red). Genome-wide significant LOD thresholds for each trait (from 10,000 permutations; $\alpha=0.01$ ) indicated by dashed lines. A zoomed in view of Linkage Group 4 (LG4) shows confidence thresholds for QTL associated with midpiece length; 1.5 LOD support interval is shown in orange, the 99\% Bayes credible interval is shown; position of the most highly associated gene. Prkar1a, is given. $F_{2}$ hybrids with recombination events within the 1.5-LOD support threshold $(n=11)$ were used for breakpoint analysis. 
recapitulates differences in midpiece length observed between the pure species (Fig. 4). Furthermore, we found that $\mathrm{F}_{2}$ males carrying at least one $P$. maniculatus allele at this locus have a significantly longer midpiece than those with none (Fig. 4 ; $t$-test: $P=4.44 \times 10^{-15}, d f=49$ ), suggesting the $P$. maniculatus allele acts in a dominant fashion. Thus, a single large-effect locus explains much of the difference in sperm midpiece length between these two species.

While we found a single significant peak associated with sperm midpiece length on linkage group 4 (Fig. 3), we found no significant quantitative trait loci (QTL) for sperm total flagellum

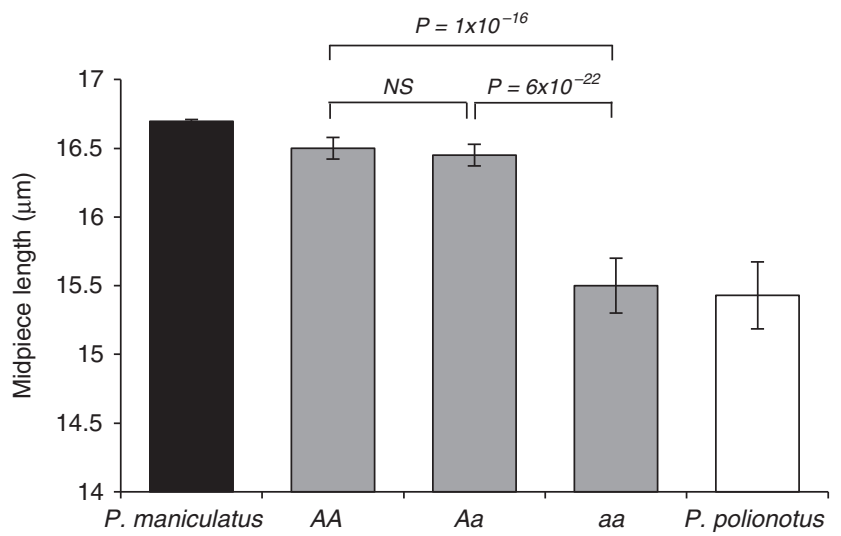

Figure 4 | Variation in sperm midpiece length between Prkar1a genotypes in hybrids relative to parental phenotypes. Mean \pm s.e. midpiece length ( $n=10$ sperm/male) of sperm harvested from $F_{2}$ hybrid offspring ( $P$. maniculatus $[n=10$; indicated as black bar $] \times P$. polionotus $[n=10$; white bar], redrawn from Fig. 1e for reference here). AA denotes males homozygous for the P. maniculatus allele at the Prkria locus $(n=61)$, Aa for heterozygous males $(n=130)$, and a for males homozygous for the $P$. polionotus allele $(n=50)$. Note truncated $y$ axis. $N S=P$ value $>0.05$, t-test. length (Fig. 3) or any measure of sperm velocity (VSL, VCL, VAP). The lack of significant QTL for total flagellum length or velocity in this cross does not suggest that variation in these traits lack a genetic basis, rather the result may be due to measurement error or an inability to detect genes of small phenotypic effect; due to the complex nature of these traits, it is likely that they are controlled by multiple genes. Moreover, velocity is a composite trait likely influenced by sperm morphology as well as other factors. We performed post-hoc scans for each of these phenotypic traits (midpiece, total flagellum, VSL, VCL and VAP with 1,000 permutations, $\alpha=0.05$ ) with each other trait, and with the genetic marker of highest linkage, as covariates; we found no additional significant QTL.

To further refine the single QTL for sperm midpiece and identify a causal gene, we enriched marker coverage in the $20 \mathrm{cM}$ region surrounding the marker of highest association by genotyping each $\mathrm{F}_{2}$ male for eight additional single nucleotide polymorphisms (SNPs; Supplementary Table 1). The increased marker density improved our QTL signal and reduced the 1.5-LOD support interval to $3.3 \mathrm{cM}$ and the $99 \%$ Bayes credible interval to a single locus containing the Prkarla gene (Fig. 3). We then confirmed this association with a genetic breakpoint analysis that included two additional SNPs flanking the marker of highest association, thereby narrowing the $3.3 \mathrm{cM}$ interval to $0.8 \mathrm{cM}$ around Prkarla (Fig. 5). The Prkarla gene encodes the R1 $\alpha$ regulatory subunit of the Protein Kinase A (PKA) holoenzyme and is the only gene within the broader $3.3 \mathrm{cM}$ confidence interval previously implicated in male fertility, sperm morphology or sperm motility ${ }^{24,25}$ (Supplementary Table 2). Therefore, Prkarla represents a strong candidate for further functional analyses.

The role of Prkar1a in Peromyscus reproduction. We found that $\mathrm{R} 1 \alpha$ is abundant and localized in the sperm midpiece in Peromyscus (Fig. 6a, Supplementary Fig. 2; and in contrast to another potential causal gene within the $0.8 \mathrm{cM}$ QTL peak, the predicted gene LOC102911133, which we found localizes to the

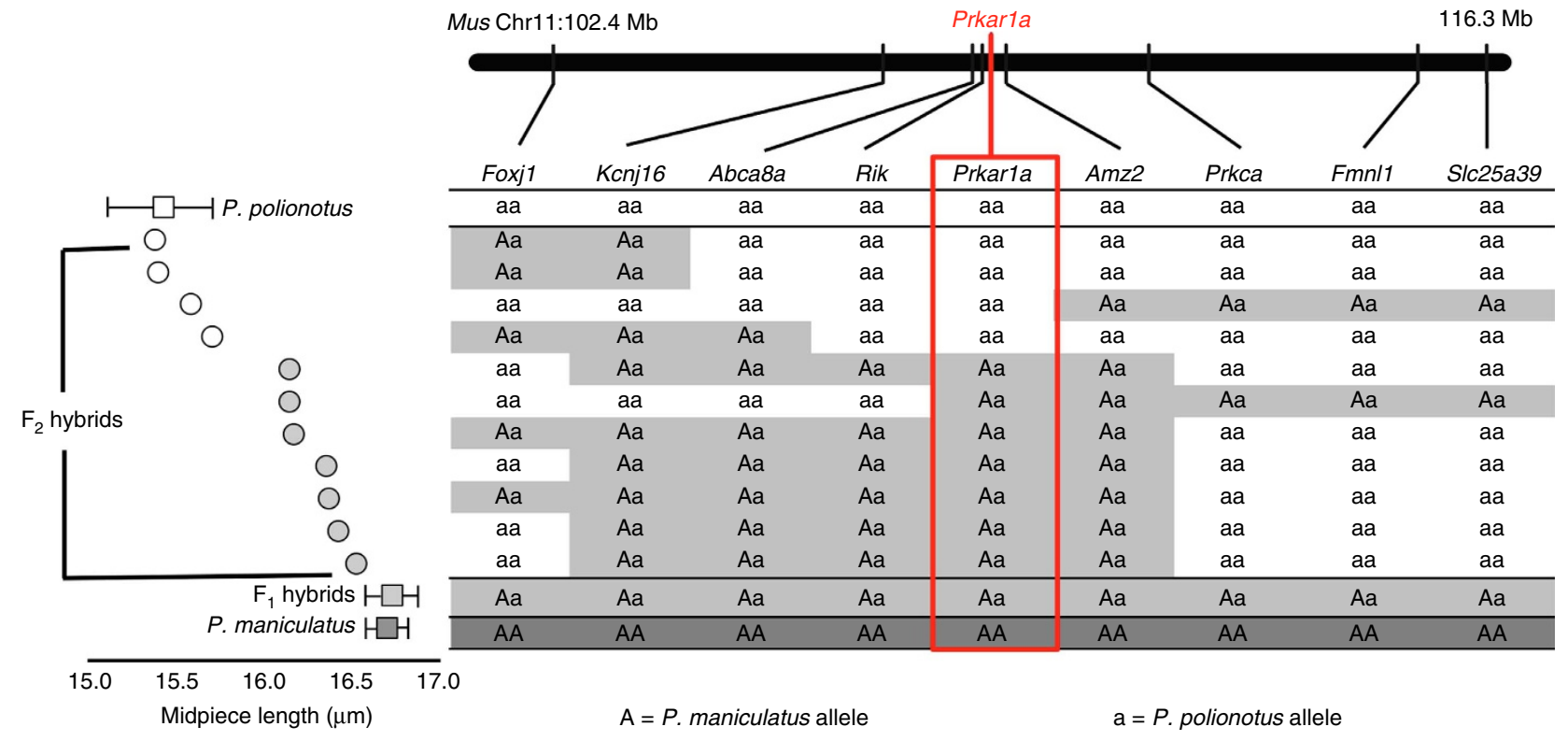

Figure 5 | Fine-scale mapping of sperm midpiece length. $F_{2}$ hybrid males $(n=11)$ that showed a recombination event in the 1.5 LOD support interval associated with the midpiece QTL (see Fig. 3); males are sorted by mean midpiece length ( $\mu \mathrm{m})$ shown by grey circles $(n=10 \mathrm{males}, n=10$ sperm/male) from shortest (top) to longest (bottom). Mean \pm s.e. midpiece length for pure P. polionotus, P. maniculatus (redrawn from Fig. 1 ) and $F_{1}$ hybrids are shown for reference. Genotypes for each individual at nine markers: Aa denotes heterozygous genotypes for the $P$. maniculatus and $P$. polionotus alleles, 'aa' for homozygous $P$. polionotus alleles. Red box highlights the Prkar1a genotype that shows a perfect association with midpiece length variation unlike neighboring loci. 
sperm head (Supplementary Note 1; Supplementary Fig. 3), consistent with studies in humans ${ }^{26}$ and rats ${ }^{27}$. To confirm the influence of Prkarla on midpiece length, we examined Mus musculus C57BL/6 animals with only a single functional copy of the gene (homozygous knockouts are inviable) ${ }^{28}$ and found that the midpiece of Prkar1a ${ }^{+1-}$ males is significantly shorter than wild type brothers (Fig. $6 \mathrm{~b}$; $t$-test: $P=4.54 \times 10^{-8}$, $d f=7, n=20$ sperm/male). These findings therefore strongly implicate the Prkarla gene as a major determinant of sperm midpiece length differences observed in Peromyscus.

We next investigated how the PKA R1 $\alpha$ subunit differed between our two focal species. First, we found no non-synonymous differences between P. maniculatus and P. polionotus in the coding exons of Prkarla mRNA (1,146 bp), suggesting that both species produce similar R1 $\alpha$ proteins. This protein is expressed throughout male germ cell development ${ }^{29}$. In whole testis samples, we found no significant differential expression of Prkarla mRNA and R1 $\alpha$ protein levels (mRNA: Supplementary Fig. 4, Bayes factor $=0.071$, Posterior Probability $=0.008, n=8$ males; protein: Fig. 7; $t$-test: $P=0.664, n=5$ males), possibly because testis samples contain cells of multiple developmental stages. However, in mature, fully a

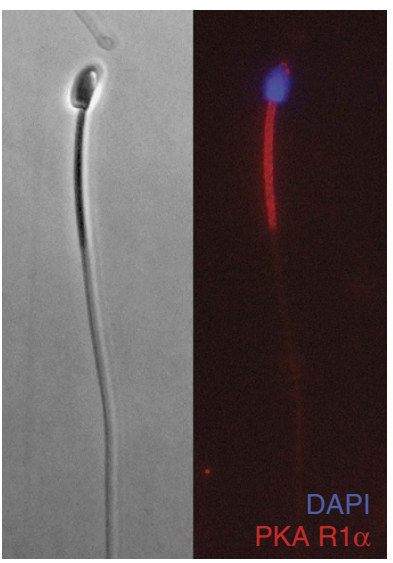

b

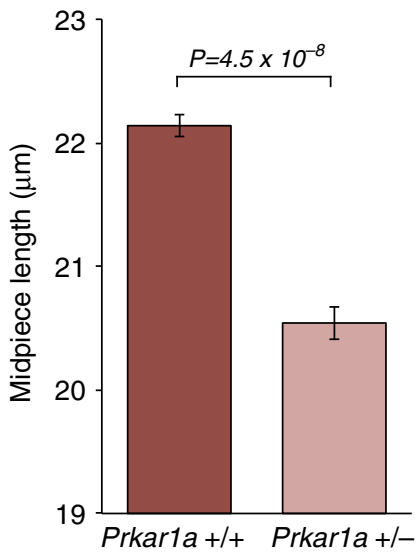

Figure 6 | PKA R1 $\alpha$ localization and effect on midpiece length. (a) PKA $\mathrm{R} 1 \alpha$ localization in mature $P$. maniculatus sperm cell $(\times 400)$; immunofluorescence of anti-PKA R1 $\alpha$ (red) and DAPI (blue).

(b) Mean \pm s.e. midpiece length of wild-type Prkar1a ${ }^{+/+}$(red) and heterozygous Prkar1a $+1-$ (pink) Mus musculus C57BL/6 sperm (t-test: $n=8$ males, $n=20$ sperm/male). Note truncated $y$ axis. developed sperm released from the caudal epididymis, we found $P$. polionotus expresses significantly more $\mathrm{R} 1 \alpha$ protein than $P$. maniculatus (Fig. 7; $t$-test: $P=0.00235, n=6$ males). These data, in combination with the knockout phenotype in Mus, suggest that changes in the expression of $\mathrm{R} 1 \alpha$ can lead to changes in sperm midpiece length.

Linking genotype, phenotype and fitness in a hybrid population. In addition to genetic mapping, our genetically heterogeneous $F_{2}$ hybrid population also enables us to test for statistical associations among traits. First, to test the prediction that sperm midpiece length influences swimming performance, we compared the mean straightline velocity (VSL) to both mean midpiece length and flagellum lengths of sperm from $\mathrm{F}_{2}$ males using a linear regression, with each trait as the independent variable. While we found no significant association with flagellum length $\left[R^{2}=0.003, P=0.29, d f=232\right]$, midpiece and VSL show a significant positive correlation [Fig. $8 \mathrm{a} ; R^{2}=0.028, P=0.0057$, $d f=232]$, which remains significant after considering flagellum length as a covariate $\left[R^{2}=0.028, P=0.012, d f=232\right.$, midpiece was the only coefficient with $P<0.05])$. Moreover, we found no significant association between midpiece length and total flagellum length in $\mathrm{F}_{2}$ males $\left(R^{2}=0.004, P=0.14, d f=232\right)$, which suggests that these two traits are genetically independent. These results show that VSL is correlated with midpiece length in Peromyscus, either because increase in midpiece length leads to

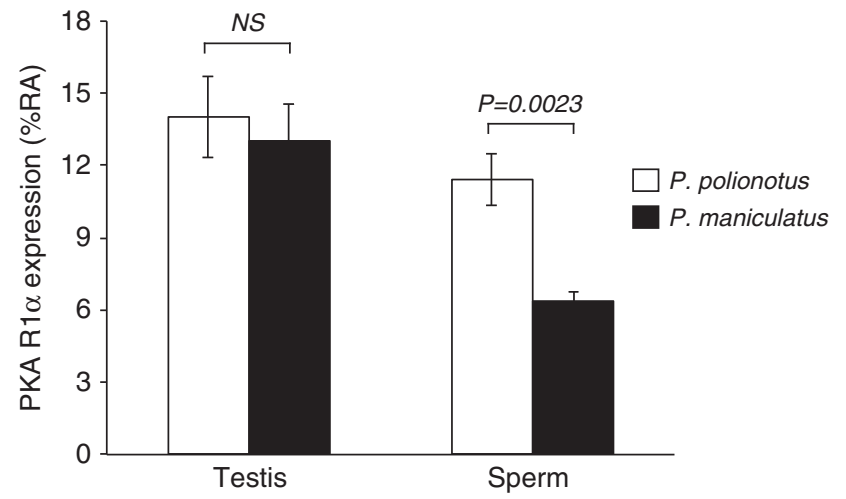

Figure 7 | PKA R1 $\alpha$. Mean \pm s.e. PKA R1 $\alpha$ protein expression as measured by percentage of relative abundance (\%RA) in testis $(n=5)$ and epididymal sperm $(n=6)$ samples from $P$. polionotus (white bars) and $P$. maniculatus (black bars) males. NS $=P$ value $>0.05, t$-test.
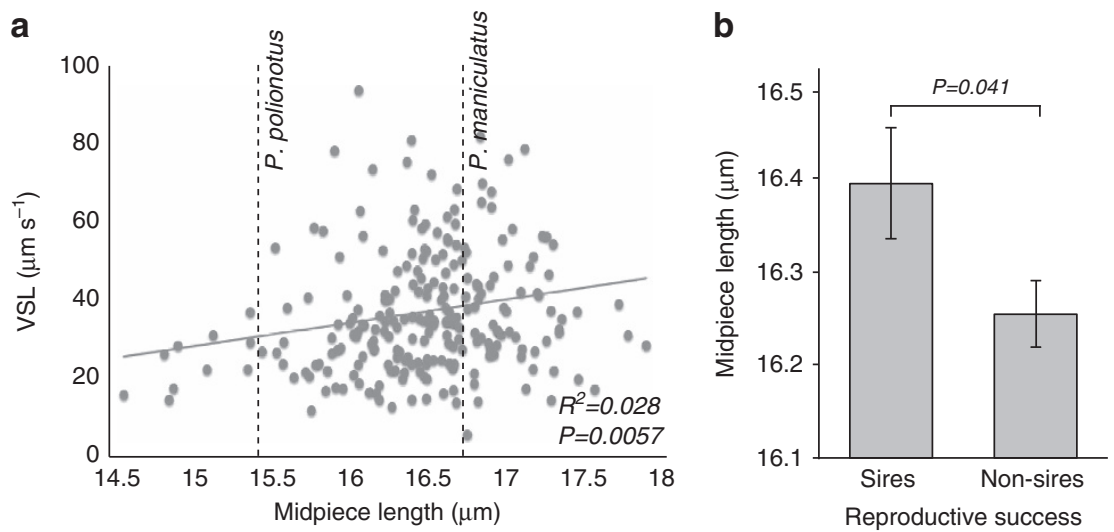

Figure 8 | Sperm performance and male fertility in $\mathbf{F}_{\mathbf{2}}$ hybrids. (a) Association between midpiece length and straight-line velocity of $F_{2}$ hybrid males (linear regression: $n=233$ males, $n=10$ sperm/male). For reference, midpiece length of each parental species is plotted as a dashed line. (b) Mean \pm s.e. sperm midpiece length of $F_{2}$ males that did $(n=85)$ and did not $(n=173)$ sire offspring (t-test). Note truncated $y$ axis. 
increased speed (that is, variation in these two traits share a pleiotropic genetic basis), or less likely, these two traits are influenced independently by tightly linked genes.

We next examined how variation at the Prkarla locus predicts sperm morphology and performance in the $\mathrm{F}_{2}$ hybrid population. We found that $\mathrm{F}_{2}$ males carrying at least one $P$. maniculatus Prkarla allele ( $A A$ or $A a$, as defined by the Prkarla SNP) produce sperm with significantly longer midpiece, as mentioned earlier (Fig. 4), but their sperm also swim with greater velocity (VSL) than sperm from males homozygous for P. polionotus Prkarla allele $(a a$; mean VSL \pm s.e.: $A A=78.7 \pm 1.9 \mu \mathrm{m} / \mathrm{s}, A a=77.5 \pm 1.1$ $\mu \mathrm{m} / \mathrm{s}, a a=73.1 \pm 1.8 \mu \mathrm{m} / \mathrm{s}, t$-test: $P_{A A-a a}=0.040, P_{\text {Aa- } a a}=0.044$, $d f=49)$. Therefore, Prkarla genotype is associated with both sperm morphology and swimming performance.

Finally, to understand how allelic and phenotypic variation influences male reproductive success, we scored which $\mathrm{F}_{2}$ males sired offspring in natural matings. We found that $\mathrm{F}_{2}$ hybrid males carrying at least one dominant $P$. maniculatus Prkarla allele were more likely to sire offspring when paired with a female for 2 weeks than those homozygous for the Prkarla $\left(\chi_{\text {AA-Aa-aa }}^{2}=6.35, P=0.042, d f=2\right)$. This is a conservative estimate of male fertility because many false negatives were likely included due to pairs that failed to mate, infanticide, female infertility and other unrelated physiological or behavioural conditions of the animals, which make an effect more difficult to detect. Moreover, this result is consistent with lower reproductive success in pure $P$. polionotus matings compared to $P$. maniculatus under similar conditions $(z=1.37, P=0.0071$, $d f=19)$. Furthermore, $F_{2}$ males who sired pups had sperm with significantly longer midpiece regions than those that did not reproduce (Fig. $8 \mathrm{~b}$; $t$-test: $P=0.041, d f=84$ ). Together, these analyses show that males carrying at least one copy of the P. maniculatus Prkar1a allele produce significantly faster sperm with longer midpieces, and also benefit from greater reproductive success, suggesting a direct link between fitness, phenotype and genetic variation at the Prkarla locus.

\section{Discussion}

When females mate with multiple partners within a reproductive cycle, males can continue to compete for reproductive success long after mating has occurred as their sperm compete for the fertilization of a limited number of ova. The strength of postcopulatory sexual selection is therefore largely determined by female mating strategy. In this study, we examined two species of Peromyscus mice with divergent mating systems. Female $P$. maniculatus mate with multiple males in a reproductive cycle, allowing for sperm of different males to compete within the female reproductive tract for fertilization success; in contrast, $P$. polionotus females mate monogamously and thus sperm competition is limited. Theory predicts that these differing competitive regimes may favour the evolution of trait divergence. Our results suggest that the difference observed in sperm midpiece length between $P$. maniculatus and $P$. polionotus confers an important reproductive advantage that improves sperm swimming performance. We first found that sperm with longer midpiece are more motile in a competitive swim-up assay. Second, within our hybrid population, we observed a positive relationship among sperm midpiece length, swimming velocity and male reproductive success. The targets of post-copulatory sexual selection can vary tremendously across taxa, but in this system, our results are consistent with the hypothesis that selection favours sperm with longer midpiece regions, consistent with findings in other species ${ }^{20-22}$.

If a simple relationship between midpiece length and fitness exists, it is puzzling why a monogamous species would not share the same sperm morphology as its promiscuous sister-species. The functional relevance of the midpiece, in both evolutionary and human fertility studies, is controversial ${ }^{30,31}$, and many closely related species vary extensively in this trait ${ }^{32-34}$. Nonetheless, while drift and/or selection acting on pleiotropic traits could lead to shorter midpiece, sperm cells with more or larger mitochondria afforded by the larger midpiece also may experience greater oxidative stress, which is known to increase mutagenesis in germ cells ${ }^{35}$. Therefore, when sperm competition is absent, such as in $P$. polionotus, the benefits conferred by producing faster sperm may not outweigh the associated costs. However, in the highly competitive environment that $P$. maniculatus sperm experience, even small increases in sperm performance could differentiate those that reproduce and those that do $\operatorname{not}^{7}$. Thus, the balance between negative and positive effects of cellular respiration in sperm may determine the relative roles of natural and sexual selection as drivers of interspecific midpiece variation seen in Peromyscus, and across animals more generally.

Using a forward-genetics approach, we identified a single gene of large effect on midpiece size, Prkar1a, which encodes for the $\mathrm{R} 1 \alpha$ regulatory subunit of the PKA. We then corroborated the role of this gene by demonstrating that lab mice with a dominant negative mutation in Prkarla have shorter midpiece than their wild-type brothers. Successful fertilization requires precise temporal and spatial regulation of PKA activity, the main downstream effector of cellular cyclic AMP concentrations, and is in part, regulated by $R 1 \alpha^{29}$. The $R 1 \alpha$ subunit is known to influence gross sperm morphology, motility and fertility in humans presenting Carney Complex (a disease associated with mutations in Prkarla) and in Mus musculus Prkarla mutants ${ }^{24}$. While most reports on Prkarla implicate negative consequences for male fertility and are associated with large-scale changes in $\mathrm{R} 1 \alpha$ expression $24,29,36-38$, our results suggest that the subtle tuning of the expression of this regulatory subunit may also confer beneficial effects. In Peromyscus, we found that $\mathrm{R} 1 \alpha$ is similarly abundant in the testis of the two focal species, yet is differentially expressed in mature sperm of $P$. maniculatus and $P$. polionotus. Considering that the heterogeneous nature of testis tissue contains germ cells at various stages of their differentiation process and Sertoli cells, it is likely that subtle difference in Prkar $1 a$ mRNA abundance or R1 $\alpha$ protein may not be detectable if expressed in a limited number of cell types. Our analysis of mature spermatozoa, however, suggests that cell type-specific R $1 \alpha$ expression differences present during later stages of Peromyscus spermatogenesis are likely to regulate midpiece length.

The rapid evolution of reproductive protein coding regions is a well-known response to post-copulatory sexual selection ${ }^{39}$; we demonstrate here that expression changes in gametes of a broadly expressed gene can also be a target of selection. Over $50 \%$ of mammalian genes are expressed in the testis and most of these genes are also expressed in other tissues ${ }^{5,6}$; therefore, cell typespecific changes in protein expression in reproductive tissues are likely to be a common mechanism by which selection in males can operate with swiftness and without deleterious effects in females or other tissues.

\section{Methods}

Mice. Wild derived Peromyscus maniculatus bairdii and Peromyscus polionotus subgriseus were originally obtained from the Peromyscus Genetic Stock Center at the University of South Carolina and have been maintained at Harvard University in accordance with guidelines established by Harvard's Institutional Animal Care and Use Committee. Adult sexually mature P. polionotus and $P$. maniculatus males were used to collect data for cross-species comparisons. In addition, we bred four mice, two $P$. polionotus males and two $P$. maniculatus females, to produce 40 first-generation $\left(F_{1}\right)$ hybrids, and then intercrossed siblings to generate secondgeneration $\left(\mathrm{F}_{2}\right)$ hybrid progeny. For genetic mapping, we used $300 \mathrm{~F}_{2}$ hybrid males 
and obtained genotypic and phenotypic data as described below. All males were sexually mature and were paired with a female prior to harvesting sperm.

Mus musculus females heterozygous for the Prkarla locus on a C57BL/6 background ${ }^{28}$ were mated to wild type C57BL/6 males to produce wild type and Prkarla ${ }^{+1-}$ offspring. These mice were a generous gift of Dr Stanley McKnight at the University of Washington.

Sperm analysis. After sacrifice via carbon dioxide overdose, we immediately removed the left caudal epididymis of each $\mathrm{F}_{2}$ male with a single cut at the intersection of the epididymis and the vas deferens. We then submersed the tissue in $1 \mathrm{ml}$ of warmed Biggers-Whitten-Whittingham (BWW) medium ${ }^{40}$, and incubated the tissue for $10 \mathrm{~min}$ at $37^{\circ} \mathrm{C}$ to release motile sperm. We then removed the epidydimal tissue, gently swirled the solution, placed $20 \mu \mathrm{l}$ of medium containing live sperm on a plastic microscope slide and covered the sample with a plastic coverslip (plastic reduces adhesion of sperm to the slide compared with glass products). We recorded $5 \mathrm{~s}$ videos of live sperm at $\times 100$ magnification under phase contrast conditions on an upright microscope (AxioImager.A1, Zeiss, Jena, Germany). We then acquired sperm swimming performance data from the videos using the Computer Assisted Sperm Analyzer plugin for NIH Image ${ }^{41}$ by measuring each motile cell in the frame $(n=4-549$ cells/male) to calculate the mean straight-line velocity (VSL), curvilinear velocity (VCL) and average path velocity (VAP). Cells aggregated into groups, dead sperm cells and those with a beating flagellum but stuck to the slide were excluded from the analysis. Sperm collected from $P$. maniculatus achieved higher velocity than $P$. polionotus sperm on all three measures (Supplementary Fig. $1 ; t$-test: $P_{\mathrm{VSL}}=0.017, P_{\mathrm{VCL}}=0.0024$, $P_{\mathrm{VAP}}=0.0039, n_{\text {male }}=9$ ).

We preserved the remaining sperm cells in $2 \%$ paraformaldehyde (Sigma-Aldrich) for morphological analysis. Following fixation, we spread $20 \mu \mathrm{l}$ of suspended sperm on a glass microscope slide and mounted the cells in Fluoromount-G (Southern Biotech). We imaged 10 sperms showing no obvious abnormalities from each male at $\times 400$ magnification under phase contrast conditions on an upright microscope (AxioImager.A1), consistent with standard practice $^{34,42-44}$. For each sperm cell from $P$. maniculatus and $P$. polionotus males we measured (1) sperm head length (the longest region of the sperm head), (2) sperm head width (the widest region of the head perpendicular to the length measure), (3) total sperm flagellum length (including midpiece, principal piece and terminal piece of cell), and (4) midpiece length (from the base of the sperm head to the midpiece-principal piece boundary; see Fig. 1a) using the curve-spline tool in the AxioVision Image Analysis Software (Zeiss). Intraclass correlation coefficients among sperm within $\mathrm{F}_{2}$ hybrid males were significant and high (midpiece $=0.651$, $P<0.05$; flagellum $=0.612, P<0.05$ ), suggesting repeatability of the measure and substantial heritability of sperm morphology, as expected from the significant differences in parental species means. Mus musculus C57BL/6 wild type and Prkarla ${ }^{+1-}$ males' sperm midpiece regions were measured and analysed identically to Peromyscus sperm.

We compared the sample means of pure $P$. maniculatus and P. polionotus sperm morphology (head length, head width, total flagellum length, midpiece length) and velocity (VSL, VCL, VAP) using two-tailed unpaired $t$-tests and adjusted alpha for multiple comparisons using Bonferroni correction.

$\mathrm{F}_{2}$ hybrid males that did not produce any sperm were excluded from all analyses incorporating sperm velocity or morphology measures, including genetic mapping; however, we used the genotypic information from these males in linkage map construction (see below). All analyses were performed in R statistical software ${ }^{45}$.

Fitness assays. We tested for an effect of sperm midpiece length on competitive success by performing three types of sperm swim-up assay: heterospecific competitions including the sperm of a $P$. maniculatus and a $P$. polionotus male, conspecific competitions between the sperm of two P. maniculatus males, and within-male competitions between the sperm of a $P$. maniculatus, including replicates of each assay. We collected live sperm (following methods above) and placed approximately equal concentrations from the two donors (for within-male assays, we added twice the volume of a similar concentration) in $0.5 \mathrm{ml} 10 \%$ polyvinylpyrrolidone in BWW medium. We took a sample of the sperm mixture ('pre-spin') and centrifuged the mixture at $150 \mathrm{~g}$ for $10 \mathrm{~min}$ at $37^{\circ} \mathrm{C}$ to pellet cells. We then collected a sample of cells just below the surface of the medium following centrifugation ('post-spin') and measured midpiece length of sperm in each sample ( $n=20$ sperm/sample). The cells near the top of the tube after spinning are those that are capable of rapidly swimming up through a viscous media. To analyse the results from these assays, we used two-tailed paired $t$-tests with Bonferroni correction to compare the mean midpiece size of a sample of sperm that entered the competition (the pre-spin sample) to the sperm that were able to swim to the top of the tube after centrifugation (the post-spin sample). This technique is commonly used to screen for the highly motile sperm most likely to achieve fertilization $^{23,46}$

To test for an effect of sperm morphology on reproductive success (Supplementary Note 1 ) we weaned each of the $\mathrm{F}_{2}$ hybrid males from their parents at 25 days of age and housed them with same-sex littermates until they were at least 68 days old and sexually mature. We then housed each male with an $F_{2}$ female chosen at random from the same grandparents as the male for at least 7 days (range 7-22 days; we found no effect of pairing length on reproductive success: unpaired two-tailed $t$-test comparing pairing length of sires and non-sires, $P=0.34$, $d f=84$ ). This time the male spent paired with a female reduced male phenotypic variability that might arise from dominance hierarchies among male littermates to minimize the differences in reproductive condition among males by exposing all to a female in the oestrus (Peromyscus estrous cycle is 5 days $^{47}$ ). Finally, we sacrificed males at 80-169 days of age to harvest sperm (we found no effect of male age on reproductive success: unpaired two-tailed $t$-test comparing mean age of sires and non-sires, $P=0.69, d f=84$ ), and recorded any observed offspring that resulted from the pairing of these $F_{2}$ males with $F_{2}$ females.

Genetic analysis. We extracted genomic DNA from liver tissue using either phenol chloroform (Automated DNA Extraction Kit, AutoGen) or DNeasy Kits (Blood \& Tissue Kit, Qiagen). We identified SNPs and assigned genotypes for each individual by double digest Restriction-site Associated DNA Sequencing (ddRADseq $^{48}$. Briefly, we digested $\sim 1 \mu \mathrm{g}$ of gDNA for each individual with two restriction endonucleases: EcoR1 and Msp1 (New England BioLabs, Ipswich). We ligated the resulting fragments to sequencing adapters containing a unique barcode for each individual male. We then pooled these barcoded fragments from multiple individuals and isolated the fragments in the size range of 280-320 bp using a Pippin Prep (Sage BioSciences). Finally, we amplified the remaining fragments using a Phusion High Fidelity PCR Kit (Thermo-Fisher) and sequenced the resulting libraries on a Genome Analyzer IIx or a HiSeq 2500 (Illumina). We recovered 1,753 informative SNP markers that consistently differed between the two parental strains used to generate the hybrid population, and which were confirmed as heterozygous in the first generation hybrids $\left(\mathrm{F}_{1}\right)$. We then pruned our marker set to exclude any markers genotyped in fewer than 100 individuals or with genotype information identical to another marker.

We conducted all genetic mapping analyses using R/qtl software ${ }^{49}$, an add-on package for $\mathrm{R}$ statistical software ${ }^{45}$. To construct a genetic linkage map, we calculated linkage distances based on the fraction of recombination events and Logarithm of Odds (LOD) scores between all SNP marker pairs. Next, we grouped markers by varying the recombination parameters until we recovered a map with 23 linkage groups containing at least five markers each (the karyotypes of both species are known [ $n=24$ chromosomes]; however, we are unable to recover the majority of the Y chromosome with the cross design employed in this study). Any markers not included in the 23 linkage groups were excluded. Finally, we refined this map by ordering the markers within each linkage group in overlapping windows of eight markers and minimizing the frequency of recombination events between markers in each window. The resulting genetic linkage map contained 504 in 23 linkage groups.

To identify QTL contributing to sperm morphology, we performed Haley-Knott regression and interval mapping analyses sequentially with 1,000 permutations and $\alpha=0.05 \mathrm{in} \mathrm{R} / \mathrm{qt}^{49}$. We found a single genomic region with a significant association for sperm midpiece length on LG4 Fig. 3); LG4 is syntenic to Mus musculus chromosome 11 and Rattus norvegicus chromosome $10^{50}$. To narrow the QTL interval, we genotyped the $\mathrm{F}_{2}$ males for additional markers within the $20 \mathrm{cM}$ region of the genome surrounding the marker most strongly associated with sperm midpiece length (Supplementary Table 1; Supplementary Note 1). This region of interest is syntenic to chromosome 11:97-114 Mb in M. musculus and chromosome 10:91-104 Mb in R. norvegicus ${ }^{51}$. We designed markers in eight genes-Foxj1, Kcnj16, Prkar1a, Prkca, Fmnl1, Klhl10, Slc25a39 and Ttll6-based on position and prioritized those implicated in male fertility, spermatogenesis, cytoskeletal organization, mitochondrial function, and/or specifically or highly expressed in the testis or during spermatogenesis ${ }^{51-53}$. We genotyped all $\mathrm{F}_{2}$ males for informative SNPs residing in each of these genes using custom designed TaqMan SNP Genotyping Assays (Thermo-Fisher), except in the case of Ttll6, where we used a restriction enzyme digest assay (all primers and TaqMan probe sequences are available in Supplementary Table 1; methods followed manufacturer's instructions). The genotype data from these eight SNP markers helped to better refine the QTL for sperm midpiece length and increased the association between genotype and phenotype (peak LOD score $=25.7$ [genome-wide LOD threshold $=3.69$ with 10,000 permutations and $\alpha=0.01]$ ). Using two measures of confidence, we found that midpiece length mapped to (1) a single marker residing in the gene, Prkarla, based on the $99 \%$ Bayes credible interval, and (2) to a $3.3 \mathrm{cM}$ region surrounding Prkarla based on 1.5 LOD support interval ${ }^{49}$. We then PCRamplified (primers available in Supplementary Table 1 ) and sequenced $\sim 1 \mathrm{~kb}$ of gDNA fragments within the genes Abca8a and $A m z 2$ in the parents of the cross and all $\mathrm{F}_{2}$ males that showed a recombination event in the surrounding region $(n=13$; Fig. 5$)$. On the basis of midpiece length of these $\mathrm{F}_{2}$ recombinants and their genotypes at the two additional markers, we were further able to narrow the QTL to $0.8 \mathrm{cM}$ by excluding association with $A m z 2$ and $A b c a 8 a$ (Fig. 5) and confirm the association between midpiece length and Prkarla.

To investigate the association between reproductive success and genotype, we compared the frequencies of $\mathrm{F}_{2}$ males homozygous for the P. maniculatus Prkar1a allele $(A A)$, the $P$. polionotus allele $(a a)$, or heterozygous $(A a)$ who sired offspring using a $3 \times 2$ Chi-squared contingency table $\left(\chi_{\text {AA-Aa-aa }}^{2}=6.35, P=0.042, d f=2\right)$.

To investigate genetic differences between $P$. maniculatus and $P$. polionotus within Prkarla, we sequenced the protein-coding region by extracting mRNA from the decapsulated testis tissue of $P$. maniculatus and $P$. polionotus males using an RNeasy Mini Kit (Qiagen), converting the mRNA to cDNA using SuperScript II 
Reverse Transcriptase (Thermo-Fisher) and a poly-T primer (T16). We amplified the entire coding sequence $(1,146 \mathrm{bp})$ using two pairs of primers (named by location in Prkar1a): Exon1c_F: 5'GCCATGGTTCCTCTGTCTTG3', Exon8_R: 5'AGAACTCATCCCCTGGCTCT3'; Exon7_F: 5'ATGTGAAACTGTGGG GCATT3' and 3'UTR_R: 5'ACGACCCAGTACTTGCCATC $3^{\prime}$.

To estimate Prkarla mRNA abundance in whole testis of $P$. maniculatus and P. polionotus $(n=8)$, we conducted an RNAseq experiment. Specifically, we extracted total RNA using the TRIzol reagent (Thermo-Fisher), purified it with RNeasy Mini Kit (Qiagen), and constructed cDNA libraries using the TruSeq RNA v2 Kit (Illumina) following manufacturer instructions. Multiplexed libraries were sequenced on an Illumina HiSeq2500 (Illumina) in paired-end mode with a read length of $150 \mathrm{bp}$ (average read depth $=30.4$ million reads/sample). We removed low quality and adaptor bases from raw reads using TrimGalore v0.4.0 (http://www.bioinformatics.babraham.ac.uk/projects/trim_galore/) and mapped the trimmed reads to the genome using the STAR RNA-Seq aligner v2.4.2a in two-pass mode ${ }^{54}$. We next obtained the P. maniculatus genome sequence and annotation from the Peromyscus Genome Project (Baylor College of Medicine; https://www.hgsc.bcm.edu/peromyscus-genome-project) and created a $P$. polionotus genome and annotation by incorporating SNPs and indels into the P. maniculatus Pman_1.0 reference (GCA_000500345.1). We estimated expression using STAR alignments in transcriptomic coordinates and the MMSEQ package v1.0.8 ${ }^{55}$, and calculated differential expression using MMDIFF ${ }^{56}$.

To validate the Prkarla mRNA estimates from RNAseq, we conducted quantitative PCR on testis of $P$. maniculatus and P. polionotus. First, we extracted mRNA from whole testis using an RNeasy Mini Kit, converted the mRNA to cDNA with SuperScript II Reverse Transcriptase (Thermo-Fisher) using a poly-T primer (T16). We then amplified a fragment with identical primer-binding sites $P$. maniculatus and $P$. polionotus using KAPA SYBR FAST Universal 2X qPCR Master Mix (Kapa Biosystems) and the following primers: $5^{\prime}$ TCCAGAAG CACAACATCCAG3' and 5'TTCATCCTCCCTGGAGTCAG3'. We conducted assays in triplicate, calculated $\triangle \mathrm{CT}$ values with TATA Binding Protein (TBP; $5^{\prime}$ CTCCCTTGTACCCTTCACCA ${ }^{\prime}$ and 5'GAAGCGCAATGGT CTTTAGG3 ${ }^{\prime}$ ), a standard control gene and validated with RNAseq. To test for significant differences in RNA abundance, between $P$. maniculatus and $P$. polionotus males, we used two-tailed unpaired $t$-tests.

Protein analysis. To localize the expression of PKA R $1 \alpha$, we fixed epididymal sperm in $2 \%$ paraformaldehyde and $1.25 \%$ glutaraldehyde on a microscope slide for $15 \mathrm{~min}$. We then washed the cells in phosphate-buffered saline with $0.1 \%$ Tween 20 (PBT) for $15 \mathrm{~min}$, and blocked in PBT with $3 \%$ bovine serum albumin (BSA) for $1 \mathrm{~h}$ at room temperature (RT). Next we incubated the cells overnight at $4^{\circ} \mathrm{C}$ with the primary antibody, PKA R1 $\alpha$ (Santa Cruz Biotechnology \#18800), which we diluted 1:100 in $\mathrm{PBT}$ with 3\% BSA. The following day we washed cells in PBT for $1 \mathrm{~h}$ at RT three times, then incubated with the secondary antibody, Alexa Fluor 546 (Thermo-Fisher \#A11056), diluted 1:500 in PBT with 3\% BSA, at 1:1,000 for $1 \mathrm{~h}$ at RT. Cells were then washed in PBT for $1 \mathrm{~h}$ at RT three times, stained with DAPI (Thermo-Fisher) to visualize DNA within cells for $15 \mathrm{~min}$ at RT, washed a final time in PBT for $15 \mathrm{~min}$, and mounted in Fluoromount-G (Southern Biotech). In addition, we controlled for non-specific binding of the secondary antibody by performing a side-by-side comparison with cells processed identically to the above methods except that instead of treating with the primary antibody, cells were solely treated with PBT with $3 \%$ BSA, the secondary antibody and DAPI. We viewed cells at $\times 400$ and $\times 1000$ magnification on an upright microscope (AxioImager.A1, Zeiss).

After sacrifice via carbon dioxide overdose, we removed one testis and stored one at $-80^{\circ} \mathrm{C}$, and submersed both caudal epididymes in $1 \mathrm{ml}$ of Modified Sperm Washing Medium (Irvine Scientific) at $37^{\circ} \mathrm{C}$ for $10 \mathrm{~min}$ to release motile sperm. We then removed the epididymes and incubated sperm for an additional $45 \mathrm{~min}$ at $37^{\circ} \mathrm{C}$ before pelleting them at $12,000 \mathrm{~g}$ for $5 \mathrm{~min}$. We washed sperm cells in phosphate buffered saline twice, and stored the sample at $-80^{\circ} \mathrm{C}$. We lysed samples at $50 \mathrm{~Hz}$ for $2 \mathrm{~min}$ in lysis buffer $(8 \mathrm{M}$ Urea, $1 \% \mathrm{SDS}, 50 \mathrm{mM}$ Tris pH 8.5, cOmplete Protease Inhibitor [Roche], PhosSTOP [Roche]), rocked for $30 \mathrm{~min}$ and centrifuged $12,000 \mathrm{~g}$ for $20 \mathrm{~min}$, all at $4^{\circ} \mathrm{C}$. Samples were then processed for multiplexed quantitative mass spectrometry analysis and analysed through the Thermo Fisher Scientific Center for Multiplexed Proteomics at Harvard Medical School. Samples were subjected to tandem protein digestion using trypsin and Lys-C protease (Thermo-Fisher), peptide labelling with Tandem Mass Tag (TMT) 10-plex reagents and peptide fractionation into 12 fractions. Multiplexed quantitative mass spectrometry data were collected on an Orbitrap Fusion mass spectrometer operating in an MS3 mode using synchronous precursor selection for the MS2 - MS3 fragmentation ${ }^{57}$. MS/MS data were searched with SEQUEST against a custom Peromyscus database with both the forward and reverse sequences, and included controlling peptide and protein level false discovery rates, assembling proteins from peptides, and protein quantification from peptides. We compared the relative abundance PKA R1 $\alpha$, normalized across all TMT reporter channels, in $P$. maniculatus and $P$. polionotus sperm and testis using two-tailed unpaired $t$-tests.

Data availability statement. The authors declare that all data supporting the findings of this study are available within the article and its Supplementary Information files or from the corresponding author upon reasonable request. Sequence data from this study have been deposited in GenBank under the accession codes KF005595 and KF005596. RNAseq data have been deposited in the GenBank/EMBL/DDBJ Sequence Read Archive under the accession code PRJ NA343919.

\section{References}

1. Chapman, T., Arnqvist, G., Bangham, J. \& Rowe, L. Sexual conflict. Trends Ecol. Evolut. 18, 41-47 (2003).

2. Hosken, D. J. \& Stockley, P. Sexual selection and genital evolution. Trends Ecol. Evolut. 19, 87-93 (2004)

3. Snook, R. Sperm in competition: not playing by the numbers. Trends Ecol. Evolut. 20, 46-53 (2005).

4. Howard, D. J. Conspecific sperm and pollen precedence and speciation. Annu. Rev. Ecol. Syst. 30, 109-132 (1999).

5. Chalmel, F. et al. The conserved transcriptome in human and rodent male gametogenesis. Proc. Natl Acad. Sci. USA 104, 8346-8351 (2007).

6. Shima, J. E., McLean, D. J., McCarrey, J. R. \& Griswold, M. D. The murine testicular transcriptome: characterizing gene expression in the testis during the progression of spermatogenesis. Biol. Reprod. 71, 319-330 (2004).

7. Birkhead, T.R., Hosken, D.J. \& Pitnick, S. Sperm Biology: An Evolutionary Perspective (Academic Press, 2008)

8. Fisher, H. S. \& Hoekstra, H. E. Competition drives cooperation among closely related sperm of deer mice. Nature 463, 801-803 (2010).

9. Fisher, H. S., Giomi, L., Hoekstra, H. E. \& Mahadevan, L. The dynamics of sperm cooperation in a competitive environment. Proc. R. Soc. B: Biol. Sci. 281, 20140296 (2014)

10. Linzey, A. V. \& Layne, J. N. Comparative morphology of spermatozoa of the rodent genus Peromyscus (Muridae). Am. Mus. Novit. 2531, 1-20 (1974).

11. Linzey, A. V. \& Layne, J. N. Comparative morphology of the male reproductive tract in the rodent genus Peromyscus (Muridae). Am. Mus. Novit. 2355, 1-47 (1969).

12. Dewsbury, D. A. \& Dewsbury, D. A. Interactions between males and their sperm during multi-male copulatory episodes of deer mice (Peromyscus maniculatus). Anim. Behav. 33, 1266-1274 (1985).

13. Birdsall, D. A. \& Nash, D. Occurrance of successful multiple insemination of females in natural populations of deer mice (Peromyscus maniculatus). Evolution 27, 106-110 (1973).

14. Dewsbury, D. A. An exercise in the prediction of monogamy in the field from laboratory data on 42 species of muroid rodents. Biologist 63, 138-162 (1981)

15. Foltz, D. W. Genetic evidence for long-term monogamy in a small rodent, Peromyscus polionotus. Am. Nat. 117, 665-675 (1981).

16. Ramm, S. A., Parker, G. A. \& Stockley, P. Sperm competition and the evolution of male reproductive anatomy in rodents. Proc. R. Soc. B: Biol. Sci. 272, 949-955 (2005).

17. Simmons, L. W. \& Fitzpatrick, J. L. Sperm wars and the evolution of male fertility. Reproduction 144, 519-534 (2012).

18. Gage, M. J. G. Mammalian sperm morphometry. Proc. R. Soc. B: Biol. Sci. 265, 97-103 (1998).

19. Cardullo, R. A. \& Baltz, J. M. Metabolic regulation in mammalian sperm: mitochondrial volume determines sperm length and flagellar beat frequency. Cell Motil. Cytoskeleton 19, 180-188 (1991).

20. Firman, R. C. \& Simmons, L. W. Sperm midpiece length predicts sperm swimming velocity in house mice. Biol. Lett. 6, 513-516 (2010).

21. Vladic, T. V. Sperm quality as reflected through morphology in salmon alternative life histories. Biol. Reprod. 66, 98-105 (2002).

22. Lüpold, S., Calhim, S., Immler, S. \& Birkhead, T. R. Sperm morphology and sperm velocity in passerine birds. Proc. R. Soc. B: Biol. Sci. 276, 1175-1181 (2009).

23. Holt, W. V., Hernandez, M., Warrell, L. \& Satake, N. The long and the short of sperm selection in vitro and in vivo: swim-up techniques select for the longer and faster swimming mammalian sperm. J. Evol. Biol. 23, 598-608 (2010).

24. Burton, K. A. et al. Haploinsufficiency at the Protein Kinase A RI $\alpha$ gene locus leads to fertility defects in male mice and men. Mol. Endocrinol. 20, 2504-2513 (2006).

25. Matzuk, M. M. \& Lamb, D. J. The biology of infertility: research advances and clinical challenges. Nat. Med. 14, 1197-1213 (2008).

26. Reinton, N. et al. Localization of a novel human A-kinase-anchoring protein, hAKAP220, during spermatogenesis. Dev. Biol. 223, 194-204 (2000).

27. Dahle, M. K., Reinton, N., Orstavik, S., Taskén, K. A. \& Taskén, K. Novel alternatively spliced mRNA (1c) of the Protein Kinase A RI $\alpha$; subunit is implicated in haploid germ cell specific expression. Mol. Reprod. Dev. 59, 11-16 (2001).

28. Willis, B. S., Niswender, C. M., Su, T., Amieux, P. S. \& McKnight, G. S. Cell-type specific expression of a dominant negative PKA mutation in mice. PLoS ONE 6, e18772 (2011).

29. Burton, K. A. \& McKnight, G. S. PKA, germ cells, and fertility. Physiology 22, 40-46 (2007) 
30. Mukai, C. \& Okuno, M. Glycolysis plays a major role for adenosine triphosphate supplementation in mouse sperm flagellar movement. Biol. Reprod. 71, 540-547 (2004)

31. Piomboni, P., Focarelli, R., Stendardi, A., Ferramosca, A. \& Zara, V. The role of mitochondria in energy production for human sperm motility. Int. J. Androl. 35, 109-124 (2011).

32. Tourmente, M., Gomendio, M. \& Roldan, E. R. Sperm competition and the evolution of sperm design in mammals. BMC Evol. Biol. 11, 12 (2011).

33. Tourmente, M., Gomendio, M., Roldan, E. R. S., Giojalas, L. C. \& Chiaraviglio, M. Sperm competition and reproductive mode influence sperm dimensions and structure among snakes. Evolution 63, 2513-2524 (2009).

34. Immler, S. \& Birkhead, T. R. Sperm competition and sperm midpiece size: no consistent pattern in passerine birds. Proc. R. Soc. B: Biol. Sci. 274, 561-568 (2007).

35. Aitken, R. J. \& Baker, M. A. Oxidative stress and male reproductive biology Reprod. Fertil. Dev. 16, 581 (2004).

36. Vijayaraghavan, S., Goueli, S. A., Davey, M. P. \& Carr, D. W. Protein kinase A-anchoring inhibitor peptides arrest mammalian sperm motility. J. Biol. Chem. 272, 4747-4752 (1997).

37. Wieacker, P. et al. Male infertility as a component of Carney complex. Andrologia 39, 196-197 (2007).

38. Hwang, K. et al. Mendelian genetics of male infertility. Ann. NY Acad. Sci. 1214, E1-E17 (2011).

39. Swanson, W. J. \& Vacquier, V. D. The rapid evolution of reproductive proteins. Nat. Rev. Genet. 3, 137-144 (2002).

40. Biggers, J. D., Whitten, W. K. \& Whittingham, D. G. in Methods in Mammalian Embryology. (ed. Daniel, J. C.) 86-116 (Freeman, 1971).

41. Wilson-Leedy, J. G. \& Ingermann, R. L. Development of a novel CASA system based on open source software for characterization of zebrafish sperm motility parameters. Theriogenology 67, 661-672 (2007).

42. Calhim, S., Immler, S. \& Birkhead, T. R. Postcopulatory sexual selection is associated with reduced variation in sperm morphology. PLoS ONE 2, e413 (2007).

43. Birkhead, T. R., Pellatt, E. J., Brekke, P., Yeates, R. \& Castillo-Juarez, H. Genetic effects on sperm design in the zebra finch. Nature 434, 383-387 (2005).

44. Firman, R. E. C. \& Simmons, L. W. Experimental evolution of sperm quality via postcopulatory sexual selection in house mice. Evolution 64, 1245-1256 (2009).

45. R Core Team. R: A Language and Environment for Statistical Computing. (R Foundation for Statistical Computing, 2010).

46. World Health Organization. WHO Laboratory Manual for the Examination and Processing of Human Semen (2010).

47. Hayssen, V. D., Van Tienhoven, A. \& Van Tienhoven, A. Asdell's Patterns of Mammalian Reproduction (Cornell University Press, 1993).

48. Peterson, B. K., Weber, J. N., Kay, E. H., Fisher, H. S. \& Hoekstra, H. E. Double digest RADseq: an inexpensive method for de novo SNP discovery and genotyping in model and non-model species. PLoS ONE 7, e37135 (2012).

49. Broman, K. W., Wu, H., Sen, S. \& Churchill, G. A. R/qtl: QTL mapping in experimental crosses. Bioinformatics 19, 889-890 (2003).

50. Ramsdell, C. M. et al. Comparative genome mapping of the deer mouse (Peromyscus maniculatus) reveals greater similarity to rat (Rattus norvegicus) than to the lab mouse (Mus musculus). BMC Evol. Biol. 8, 65 (2008).

51. Karolchik, D. et al. The UCSC Genome Browser database: 2014 update. Nucleic Acids Res. 42, D764-D770 (2014).

52. The UniProt Consortium. UniProt: a hub for protein information. Nucleic Acids Res. 43, D204-D212 (2010)

53. Blake, J. A. et al. The Mouse Genome Database: integration of and access to knowledge about the laboratory mouse. Nucleic Acids Res. 42, D810-D817 (2014).
54. Dobin, A. et al. STAR: ultrafast universal RNA-seq aligner. Bioinformatics 29, 15-21 (2013)

55. Turro, E., Goncalves, A., Coin, L. J. M., Richardson, S. \& Lewin, A. Haplotype and isoform specific expression estimation using multi-mapping RNA-seq reads. Genome Biol. 12, R13 (2011).

56. Turro, E., Astle, W. J. \& Tavaré, S. Flexible analysis of RNA-seq data using mixed effects models. Bioinformatics 30, 180-188 (2014).

57. McAlister, G. C. et al. MultiNotch MS3 enables accurate, sensitive, and multiplexed detection of differential expression across cancer cell line proteomes. Anal. Chem. 86, 7150-7158 (2014).

\section{Acknowledgements}

We thank S. McKnight for generously donating Prkarla ${ }^{+/-}$mice; R. Mallarino, B. Peterson and J. Weber for experimental advice; A. Bree, E. Lievens, C. Scholes, J. Weaver and C. Xu, and for technical assistance; and S. McKnight, K. Peichel, M. Ryan and S. Suarez for comments on earlier versions of this manuscript. Research was funded by an NIH Ruth Kirschstein National Research Service Award (NIGM084719) and an NIH Pathway to Independence Award to H.S.F. (NICHD071972); an NSF Graduate Research Fellowship and an NSF Doctoral Dissertation Improvement Grant to E.J.-P.; European Molecular Biology Organization Postdoctoral Fellowship and a Human Frontier Science Program Long-term Fellowship to J.-M.L.; and an Arnold and Mabel Beckman Foundation Young Investigator Award to H.E.H. H.E.H. is an Investigator at the Howard Hughes Medical Institute.

\section{Author contributions}

H.S.F. and H.E.H. conceived of and designed the study; H.S.F. bred, processed and genotyped Peromyscus, performed QTL and fine-scale mapping, protein localization and quantification; E.J.-P. measured sperm morphology, bred and processed Mus; J.-M. L. designed and analysed the RNA-seq experiments; H.S.F. and H.E.H. interpreted the results and wrote the paper.

\section{Additional information}

Supplementary Information accompanies this paper at http://www.nature.com/ naturecommunications

Competing financial interests: The authors declare no competing financial interests

Reprints and permission information is available online at http://npg.nature.com/ reprintsandpermissions/

How to cite this article: Fisher, H.S. et al. The genetic basis and fitness consequences of sperm midpiece size in deer mice. Nat. Commun. 7, 13652 doi: 10.1038/ncomms13652 (2016).

Publisher's note: Springer Nature remains neutral with regard to jurisdictional claims in published maps and institutional affiliations.

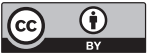

This work is licensed under a Creative Commons Attribution 4.0 International License. The images or other third party material in this article are included in the article's Creative Commons license, unless indicated otherwise in the credit line; if the material is not included under the Creative Commons license, users will need to obtain permission from the license holder to reproduce the material. To view a copy of this license, visit http://creativecommons.org/licenses/by/4.0/

C The Author(s) 2016 